\title{
Seismic Vulnerability Analysis of a Coupled Tank-Piping System by Means of Hybrid Simulation and Acoustic Emission
}

\author{
O. Sayginer ${ }^{1}\left(\mathbb{D} \cdot\right.$ R. di Filippo ${ }^{1} \cdot$ A. Lecoq ${ }^{1} \cdot$ A. Marino ${ }^{2} \cdot$ O.S. Bursi ${ }^{1}$
}

Received: 27 August 2019 / Accepted: 6 August 2020 / Published online: 1 September 2020

(C) The Author(s) 2020

\begin{abstract}
In order to shed light on the seismic response of complex industrial plants, advanced finite element models should take into account both multicomponents and relevant coupling effects. These models are usually computationally expensive and rely on significant computational resources. Moreover, the relationships between seismic action, system response and relevant damage levels are often characterized by a high level of nonlinearity, which requires a solid background of experimental data. Vulnerability and reliability analyses both depend on the adoption of a significant number of seismic waveforms that are generally not available when seismic risk evaluation is strictly site-specific. In addition, detection of most vulnerable components, i.e., pipe bends and welding points, is an important step to prevent leakage events. In order to handle these issues, a methodology based on a stochastic seismic ground motion model, hybrid simulation and acoustic emission is presented in this paper. The seismic model is able to generate synthetic ground motions coherent with site-specific analysis. In greater detail, the system is composed of a steel slender tank, i.e., the numerical substructure, and a piping network connected through a bolted flange joint, i.e., the physical substructure. Moreover, to monitor the seismic performance of the pipeline and harness the use of sensor technology, acoustic emission sensors are placed through the pipeline. Thus, real-time acoustic emission signals of the system under study are acquired using acoustic emission sensors. Moreover, in addition to seismic events, also a severe monotonic loading is exerted on the physical substructure. As a result, deformation levels of each critical component were investigated; and the processing of acoustic emission signals provided a more in-depth view of the damage of the analysed components.
\end{abstract}

Keywords Piping · Piping elbows $\cdot$ Finite element model $\cdot$ Hybrid simulation $\cdot$ Acoustic emission $\cdot$ Seismic risk $\cdot$ Hazard analysis $\cdot$ Engineering simulation $\cdot$ Simulation $\cdot$ Damage $\cdot$ Industrial plants $\cdot$ Leakage $\cdot$ Signals $\cdot$ Steel $\cdot$ Strain gages

\section{Introduction}

Natural catastrophe can trigger serious consequences in industrial plants, with reference to both structural and non-structural failures resulting in the so-called Natech events [1]. Among other natural catastrophes, seismic events represent a significant share of possible causes.

However, industrial plants are made of an high number of different components with dissimilar characteristics, overall resistances and associated hazards. A very common component

O. Sayginer

osman.sayginer@unitn.it

1 Department of Civil, Environment and Mechanical, Engineering, University of Trento, Via Mesiano 77, 38050 Trento, Italy

2 The Italian National Institute for Insurance against Accidents at Work, Via del Torraccio di Torrenova 7, 00133 Rome, Italy of these facilities are pipelines, whose vulnerability becomes an important matter especially when filled with hazardous material, like in petrochemical plants. As a matter of fact, in these circumstances, the failure scenario of a loss of containment (LoC) can result in significant adverse effects on nearby communities and the environment. With reference to LoC prevention, this paper presents an experimental investigation of a realistic tank-piping system in order to assess its seismic performances with a special focus on vulnerable components, like bolted flange joints (BFJs), Tee joints and pipe bends; see [2, 3].

A very useful tool for seismic risk assessment is the performance-based earthquake engineering (PBEE) methodology [4]. According to [5], the PBEE approach is affected by two main sources of uncertainty, i.e., ergodic and non-ergodic uncertainties. More precisely, ergodic variables like seismic intensity measures (IMs) are statistically independent in time domain and, their accuracy, increases with the number of samples. Conversely, structural uncertainties like soil-structure 


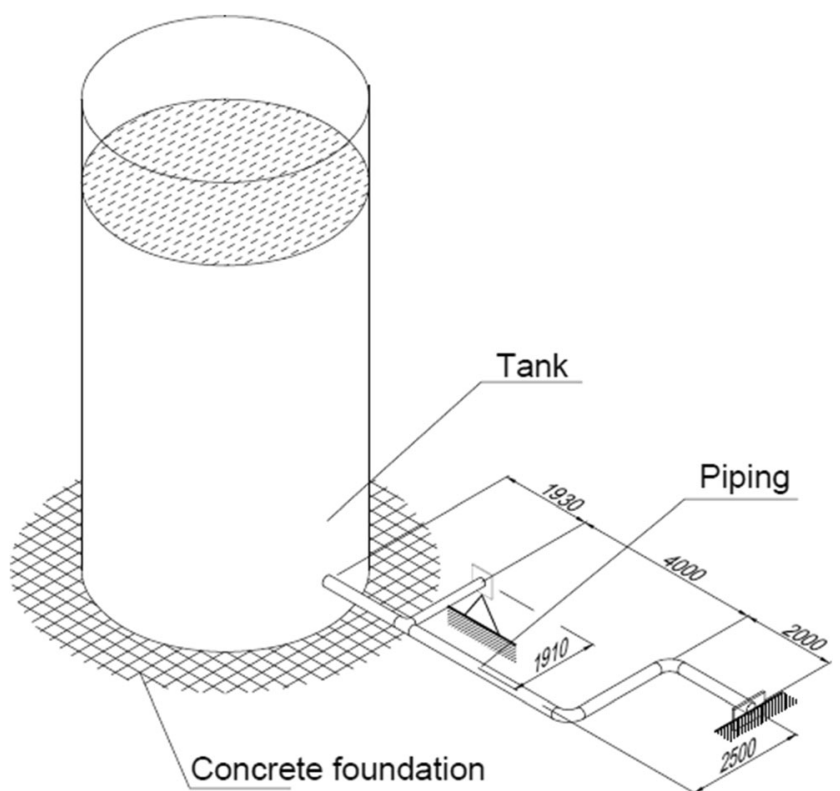

Fig. 1 Realistic drawing of the tank-piping system and components, measures in $\mathrm{mm}$

interaction, material characteristics, finite element $(\mathrm{FE})$ models, etc. are not statistically independent or even completely invariant in time; therefore, the averaging of results of the highest possible number of different analyses does not reduce uncertainties propagation. Thus, uncertainties in IMs can be reduced with the adoption of a sufficiently high number of seismic action samples, i.e., ground motion signals. However, the number of natural seismic records is quite limited and, procedures like intensity scaling, can lead to additional errors [6].

Along these lines, in this paper, we present a procedure to reduce both ergodic and nonergodic uncertainties. In particular, ergodic uncertainties are limited with the adoption of synthetic ground motions generated on the underpinning sitespecific probabilistic seismic hazard analysis (PSHA) [7]. In order to achieve that, we calibrated the stochastic ground motion model, as formulated by [8], against a set of natural accelerograms compatible with the results of the aforementioned PSHA. On the other hand, non-ergodic uncertainties are reduced by means of experimental data provided by component cyclic testing [9] and hybrid simulation (HS) on a coupled tank-piping system. Specifically, the hybrid model of the system under study combines numerical (NSs) and physical substructures (PSs). More precisely, following the approach of $[10,11]$, the steel tank represents the NS and the piping network the PS. Furthermore, in order to both
Table 1 Mechanical properties and the geometry of the Tee joint

\begin{tabular}{lllll}
\hline Design & Diameter $(\mathrm{mm})$ & Thickness $(\mathrm{mm})$ & Length $(\mathrm{mm})$ & Material \\
\hline Main pipe & $219.1\left(8^{\prime \prime}\right)$ & $8.2\left(0.32^{\prime \prime}\right)$ & $1568\left(61.7^{\prime \prime}\right)$ & $\begin{array}{l}\text { P355N steel } \\
\text { fy }=380 \mathrm{MPa}\end{array}$ \\
Branch pipe & $168.3\left(6^{\prime \prime}\right)$ & $7.1\left(0.28^{\prime \prime}\right)$ & $678\left(26.7^{\prime \prime}\right)$ & $\begin{array}{l}\text { P355N steel } \\
\text { fy }=380 \mathrm{MPa}\end{array}$ \\
\hline
\end{tabular}

Fig. 2 Probabilistic seismic hazard deaggregation analysis for Hanford, California (US)

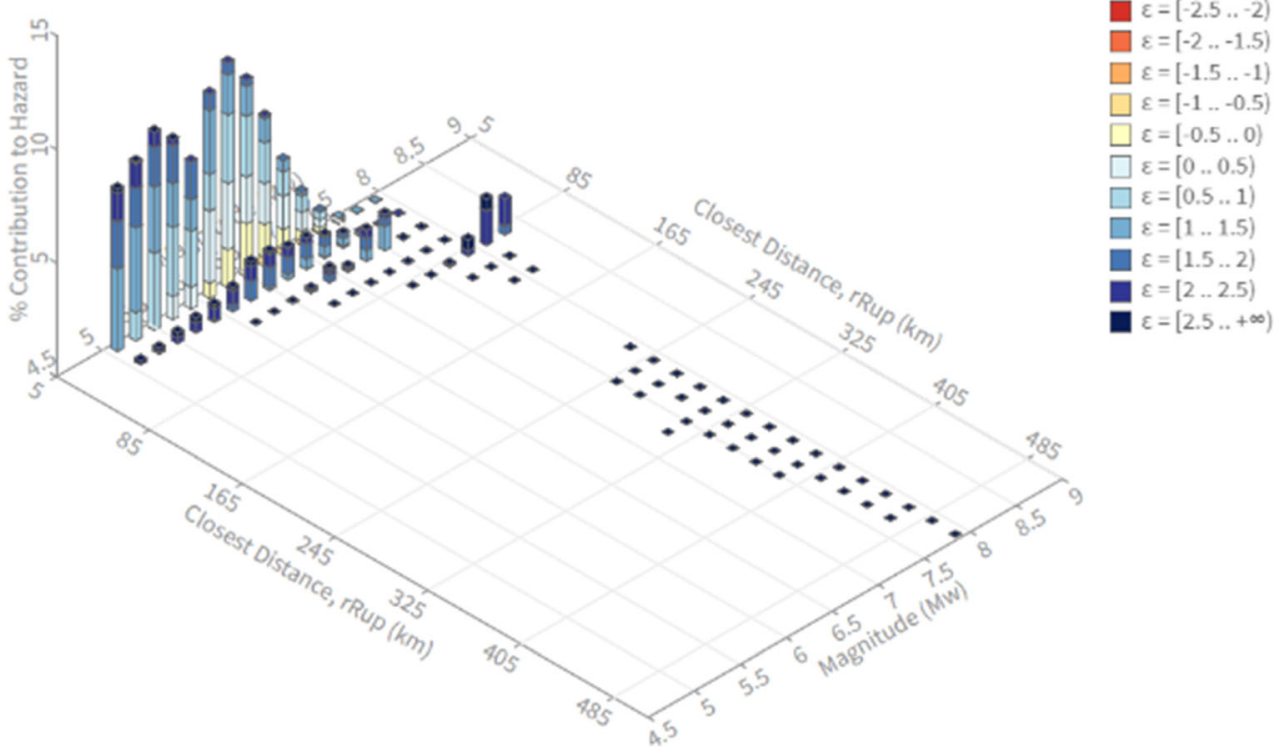


Table 2 Set of compatible accelerograms

\begin{tabular}{llll}
\hline Earthquake name & Station name & Magnitude (M) & Distance (R) (km) \\
\hline Northridge-01 & Canoga Park - Topanga Can & 6.69 & 14.7 \\
Northridge-01 & Canyon Country - W Lost Cany & 6.69 & 12.44 \\
Northridge-01 & N Hollywood - Coldwater Can & 6.69 & 12.51 \\
Northridge-01 & Northridge - 17,645 Saticoy & 6.69 & 12.09 \\
Northridge-01 & Simi Valley - Katherine Rd & 6.69 & 13.42 \\
Northridge-01" & Sun Valley - Roscoe Blvd & 6.69 & 10.05 \\
Northridge01 & Sunland - Mt Gleason Ave & 6.69 & 13.35 \\
Northridge02 & Pacoima Kagel Canyon & 6.05 & 11.34 \\
\hline
\end{tabular}

evaluate inelastic phenomena of the piping system and to detect and localize crack events, we employ a set of acoustic emission sensors. This type of sensors is widely used in industrial applications to monitoring pipelines and other types of vessels [12]. As a result, damage levels can also clearly correlate to external loading.

The remainder of the paper is arranged into five main sections. The first one contains a description of the coupled tankpiping system under study while the second one presents the ground motion model of the seismic input. The third section covers in depth the experimental approach used for HS. The fourth section provides information about sensor installation and the use of acoustic emission. Relevant results of the experimental work are provided in the fifth section. Finally, in the last section, main conclusions are drawn and possible future developments are mentioned.

\section{Case Study}

The selected case study is composed of a coupled tank-piping system. In detail, the tank is made by steel and placed unanchored on a concrete foundation, with a height of $14 \mathrm{~m}$ and an $8 \mathrm{~m}$ diameter. The tank is assumed to be filled with oil. Moreover, the tank is connected to the piping network via a bolted flange joint. On the other hand, the piping network is made by API 5 L X52 steel, equivalent to the European P355 steel. Besides, it encompasses 8" (outer diameter: $219.08 \mathrm{~mm}$; thickness: $8.18 \mathrm{~mm}$ ) and 6" (outer diameter: $168.28 \mathrm{~mm}$; thickness: $7.11 \mathrm{~mm}$ ) schedule 40 pipes. Furthermore, the piping network encompasses several critical components, mainly

Table 3 Model parameters for stochastic ground motion

\begin{tabular}{ll}
\hline $\mathrm{I}_{\mathrm{a}}$ & Arias intensity \\
$\mathrm{D}_{5-95}$ & Time interval of $95 \%$ of the $\mathrm{I}_{\mathrm{a}}$ \\
$t_{\text {mid }}$ & Time at which $45 \%$ of the $\mathrm{I}_{\mathrm{a}}$ is reached \\
$\omega_{\text {mid }}$ & Filter frequency at $\mathrm{t}_{\text {mid }}$ \\
$\zeta_{\mathrm{f}}$, & Filter damping ratio (constant) \\
$\omega^{\prime}$ & Rate of change of the filter frequency with time \\
\hline
\end{tabular}

two elbows, a bolted flange joint, and a Tee joint. The design of the tank-piping system is given in Fig. 1.

The piping material is P355 steel (Grade X52) with yielding stress of $380 \mathrm{MPa}$ while the fitting steel has a nominal yield stress of $355 \mathrm{MPa}$. More in detail, the relevant geometric and mechanical characteristics of the Tee joint are given in Table 1. Moreover, the internal pressure of the pipeline is kept at 3.2 $\mathrm{MPa}$ in order to investigate the pressure effect on the mechanical properties of the joints.

\section{Seismic Input}

Intrinsically, a seismic signal can vary in a several different characteristics scales. For this reason, it is quite difficult to generate a realistic seismic signal. Thus, the characterization of a seismic action requires taking into account an high level of uncertainty. Even though lowering the uncertainty of the seismic input by considering a high number of seismic signals is an option, natural records are limited. For this reason, in order to use a number of seismic signals that are higher than the available set of coherent natural accelerograms, we decided to use synthetic ones. Thus, in this study, we implemented a multi-step procedure to calibrate a stochastic ground motion model in order to generate coherent synthetic ground motions.

As the first step of this procedure, our case study is supposed to be located in Hanford, California (US), and a probabilistic seismic hazard (PSHA) analysis [7] is carried out. The analysis is based on the United States Geological Survey

Table 4 Distributions of model parameters

\begin{tabular}{lllll}
\hline Name & Distribution & LB & UB & Units \\
\hline$I_{a}$ & Uniform & 0.019 & 3.992 & $\mathrm{~m}^{2} / \mathrm{s}^{3}$ \\
$D_{5-95}$ & Uniform & 5.083 & 16.810 & $\mathrm{~s}$ \\
$T_{45}$ & Uniform & 1.596 & 5.664 & $\mathrm{~s}$ \\
$\omega_{\text {mid }}$ & Uniform & 14.620 & 31.000 & $\mathrm{rad} / \mathrm{s}$ \\
$\zeta$ & Uniform & 0.074 & 0.557 & - \\
\hline
\end{tabular}




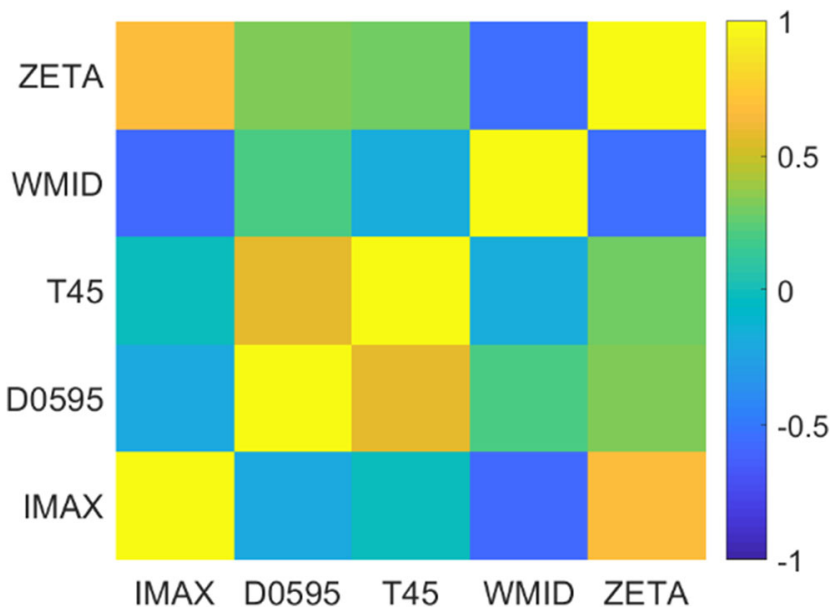

Fig. 3 Linear correlation of stochastic parameters

(USGS) database, and the relevant PSHA results are depicted in Fig. 2.

As a result of the deaggregation analysis given in Fig. 2, mode values for magnitude (M) and distance from the fault (R) read 6.3 and $10.75 \mathrm{~km}$, respectively. Based on these two values, a set of seven compatible accelerograms is chosen and their relevant $\mathrm{R}$ and $\mathrm{M}$ values are given in given in Table 2 .

As can be seen from Table 2, all the different signals refer to the same event, that is the Northridge earthquake since we prefer to consider a single event in order to limit the variability of the seismic input. In fact, the stochastic ground motion model that we adopt in this work is already capable of generating a sufficient level of variability. More in detail, the model was developed by [8] and generates synthetic ground motions processing 6 different parameters, listed in Table 3, by means of the following main expression:

$a_{g}(t)=q(t, \boldsymbol{\alpha})\left[\frac{1}{\sigma_{f}(t)} \int_{-\infty}^{t} h(t-\tau, \boldsymbol{\lambda}(\tau)) \omega(\tau) d \tau\right]$

Where $\omega(\tau)$ is the baseline white noise while $\widehat{\alpha}$ is defined by means of:

$\widehat{\alpha}=\arg \min _{\alpha}\left(\left|I_{a}\left(t_{45}\right)-\widehat{I}_{a}\left(t_{45}\right)\right|+\left|I_{a}\left(t_{95}\right)-\widehat{I}_{a}\left(t_{95}\right)\right|\right)$

Fig. 4 Simplified MATLAB FE model, scheme of input/output

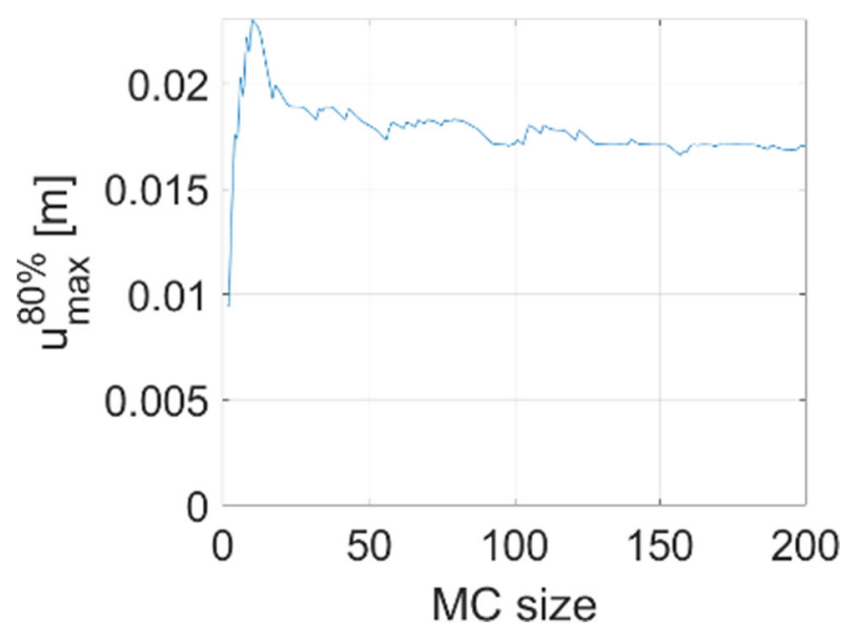

Fig. 5 Convergence of the 80th percentile of maximum sliding displacement

Furthermore, $h(t-\tau, \boldsymbol{\lambda}(\tau))$, i.e., the Impulse Response Function (IRF) of a linear time-varying filter, can be expressed as follows:

$h(t-\tau, \lambda(\tau))=f\left(\omega_{f}, \zeta_{f}\right)$

where:

$\omega_{f}=\omega_{\text {mid }}+\omega^{\prime}\left(t-t_{\text {mid }}\right)$

Following the calibration process described in [8], we evaluate the model parameters able to generate a set of accelerograms coherent to those listed in Table 2. Once these values are calculated, we make two hypotheses in order to define a statistical distribution for each one of the model parameters. The first hypothesis is to consider the parameters statistically uncorrelated. With reference to this, the actual linear correlation coefficients between the different parameters are shown in Fig. 3. The second hypothesis is the choice of uniform distributions to describe the probability distribution of all the parameters, with the only exception of $\omega^{\prime}$ that we consider equal to a specific constant value of $-0.568 \mathrm{rad} / \mathrm{s}^{2}$. With regard to the uniformly distributed parameters, their lowest and highest boundaries (LB and UB), set to encompasses 


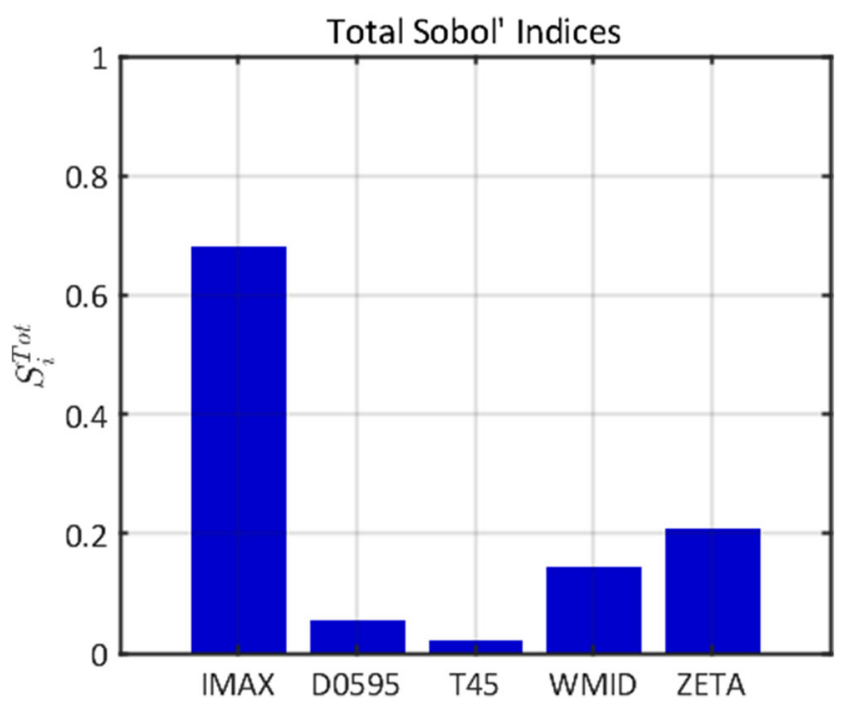

Fig. 6 Total Sobol' indices

all the values retrieved from the aforementioned calibration process, are listed in Table 4.

From Fig. 3, it can be seen that the hypothesis of uncorrelated parameters is not so dissimilar from reality. Nevertheless, to prepare the experimental campaign, we have to select the proper seismic input taking into account the limited number of tests practically manageable. For this reason, a preliminary step is to reduce the space of these parameters selecting those with the highest influence on the system seismic response. In order to select a simple parameter to identify the seismic response with the maximum sliding displacement of the steel tank, is chosen, see Fig. 4 for reference. As a matter of fact, it is straightforward that the sliding displacement a reliable benchmark of the external load on the piping system.

Thus, we present the procedure to perform a global sensitivity analysis (GSA) and select the seismic input for experimental tests as described in [13].

As the first step, once the choice of inputs and outputs, respectively $x$ and $y$, is done, it is possible to formalize them by means of:

$x \in X_{E D}=\left\{I_{a}, D_{5-95}, T_{45}, \omega_{\text {mid }}, \zeta\right\}$

$y \in Y_{E D}=u_{\max }^{80 \%}$

Table 5 Constant parameters

\begin{tabular}{lll}
\hline Name & Value & Units \\
\hline$D_{5-95}$ & 10.441 & $\mathrm{~s}$ \\
$T_{45}$ & 3.700 & $\mathrm{~s}$ \\
$\dot{\omega}$ & -0.568 & $\mathrm{rad} / \mathrm{s}^{2}$ \\
\hline
\end{tabular}

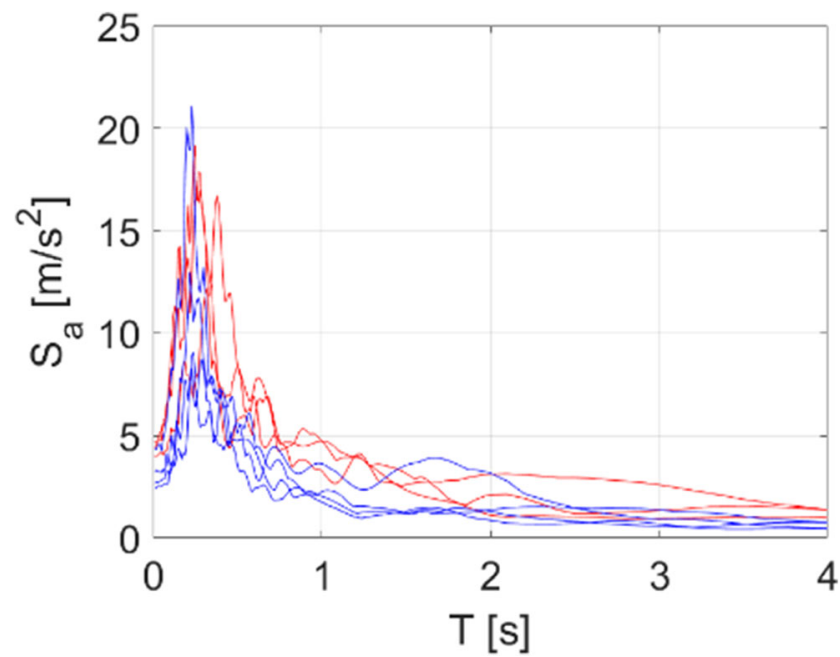

Fig. 7 Spectral accelerations of ULS (red) and SLS (blue) synthetic ground motions

Thus, a set of $2 \mathrm{e} 2$ stochastic ground motion model parameters is generated, according to the distributions defined in Table 4, in order to perform a Monte Carlo (MC) analysis with a simplified MATLAB model. However, this set is expanded to a total of $4 \mathrm{e} 4$ artificial accelerograms combining each of the $2 \mathrm{e} 2$ parameter realizations with $2 \mathrm{e} 2$ different baseline noises, $\omega(\tau)$. A preliminary analysis on a smaller set is realized with a convergence check upon the $80 \%$ percentile of the maximum displacements, as depicted in Fig. 5. Therefore, a GSA is performed to assess the individual contributions of each input variable to the total variance of the model response. A GSA can be performed with Sobol' decomposition (also called general ANOVA decomposition) of the computational model, which allows one to decompose a full model response in submodels, according to [14].

The Sobol' index for each subset of input variables $\boldsymbol{u}$ can be written as follows:

$S_{u}=\frac{D_{u}}{D}$

As stated in [15] polynomial chaos expansion (PCE) methodology provides an effective way to estimate the Sobol' indices by post-processing the polynomial coefficients. The analytical formulation of PCE method can be written as follows:

$\widehat{y}(\boldsymbol{x})=\mathcal{M}^{P C}(\boldsymbol{x})=\sum_{\boldsymbol{\alpha} \in \mathcal{A}^{M, p}} y_{\boldsymbol{\alpha}} \Psi_{\boldsymbol{\alpha}}(\boldsymbol{x})$

Where $\Psi_{\alpha}$ is a multivariate polynomial with multi-index vector $\alpha, y_{\alpha}$ is the coefficient of a single multivariate polynomial and $\mathcal{A}^{M, p}=\left\{\boldsymbol{\alpha} \in \mathbb{N}^{M}:|\boldsymbol{\alpha}| \leq p\right\}$ is the truncated set of multi- 


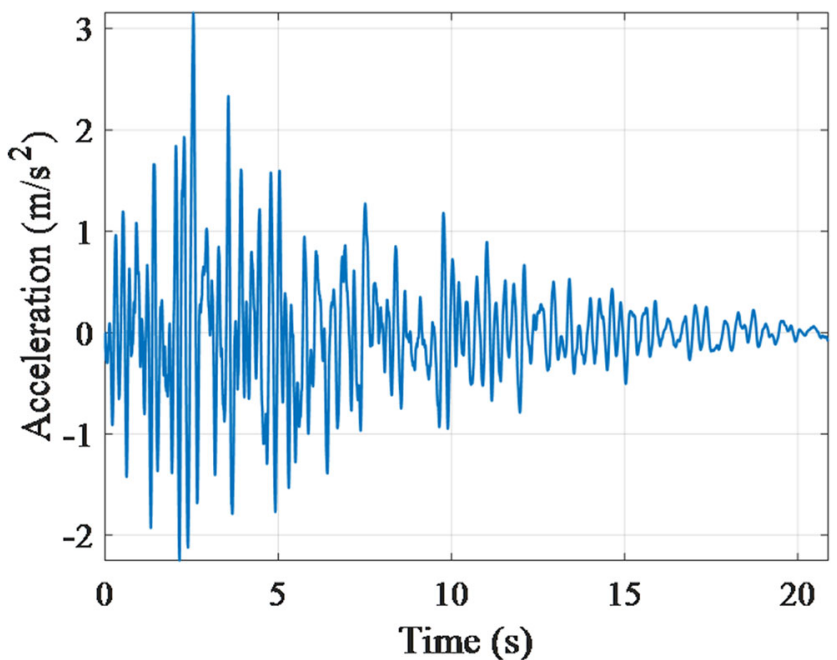

Fig. 8 Seismic Input Signal used for hybrid simulation

indices. In particular, the relevant variance can be expressed as:

$$
\operatorname{Var}\left[\mathcal{M}^{P C}(\boldsymbol{x})\right]=\sum_{\substack{\alpha \in \mathcal{A}^{M, p} \\ \alpha \neq 0}} y_{\alpha}^{2}
$$

By means of equations (7) and (9) we can write Total Sobol' indices as:

$$
\widehat{S}_{i}^{T, P C}=\frac{\sum_{\alpha \in \mathcal{A}_{i}^{T}} \hat{y}_{\alpha}^{2}}{\sum_{\substack{\alpha \in \mathcal{A} \\ \alpha \neq 0}} \hat{y}_{\alpha}^{2}}, \quad \mathcal{A}_{i}^{T}=\left\{\alpha \in \mathcal{A}: \alpha_{i}>0\right\}
$$

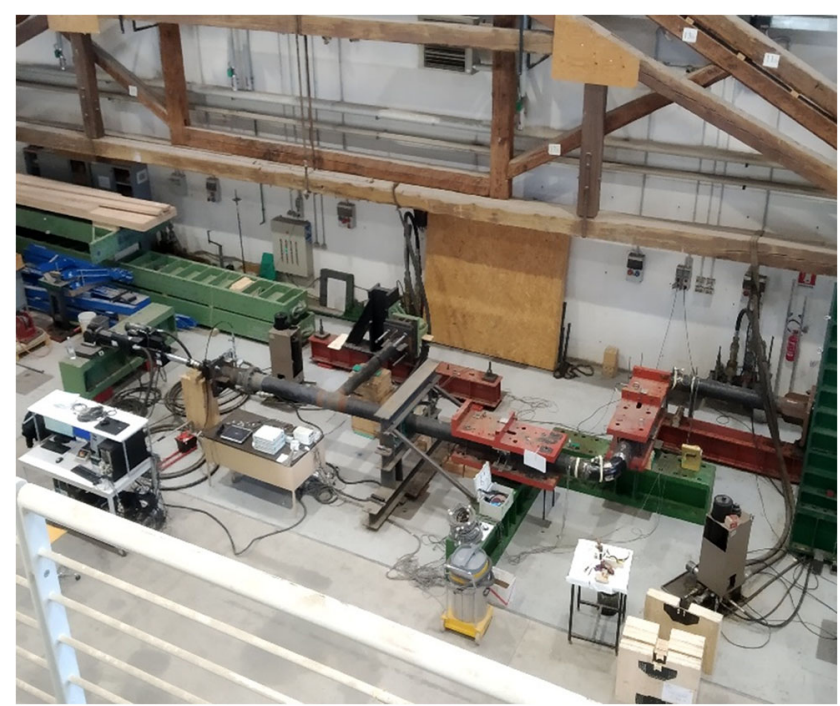

Fig. 10 Experimental setup consisting of the physical substructure and the transfer system

Finally, the relevant values of Sobol' indices evaluated by equation (10) are shown in Fig. 6:

From Fig. 6 it is possible to notice that three parameters generate most part of the output variance, i.e. $I_{a}, \omega_{\text {mid }}$ and $\zeta$. This is somehow expected since they represent the most significant part of the intensity of accelerograms physical effects. Besides, based on GSA results, these three parameters are chosen to vary according to the statistical distributions defined in Table 4, while the remaining three are fixed at their average value, as reported in Table 5.
Fig. 9 Experimental setup configuration consisting of the physical substructure and the transfer system

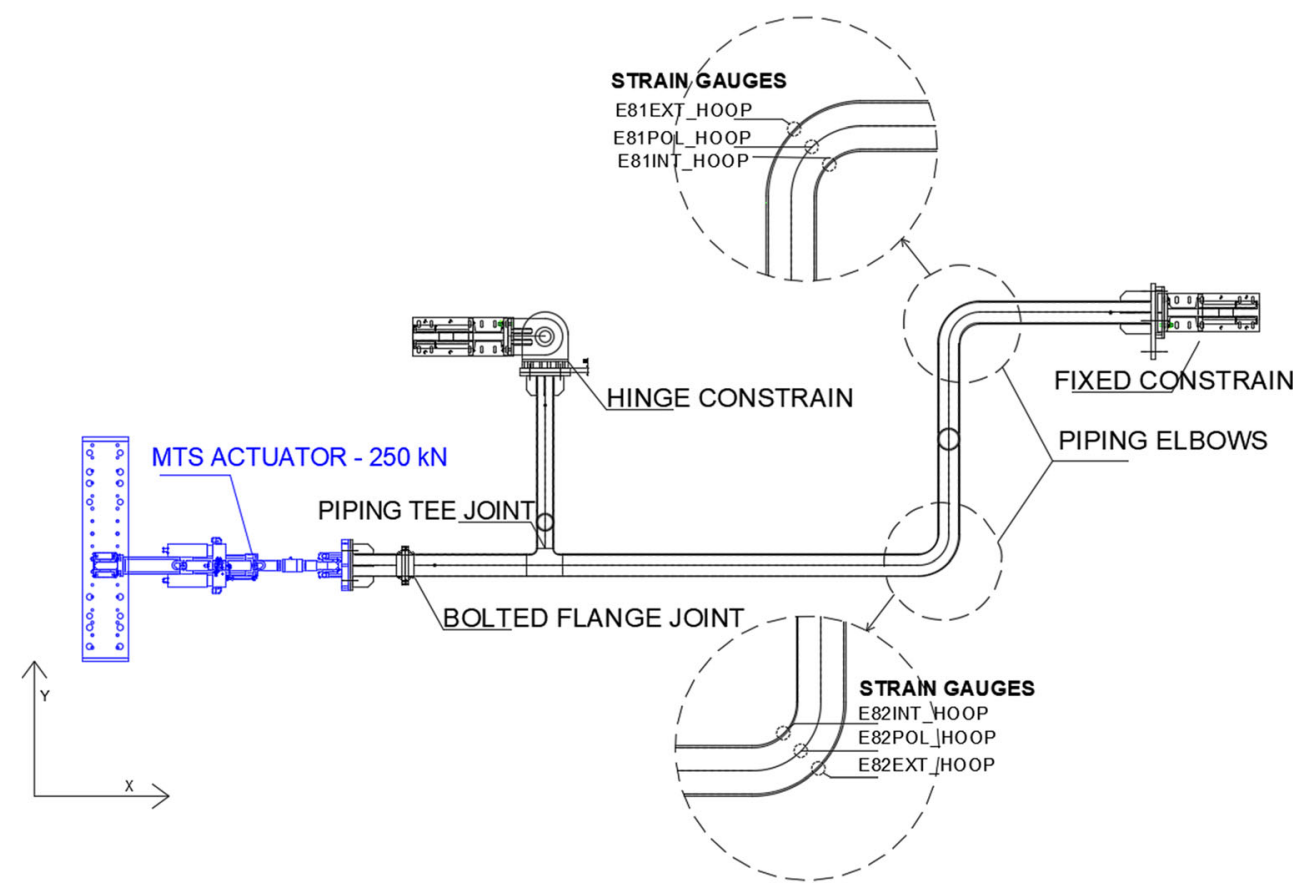



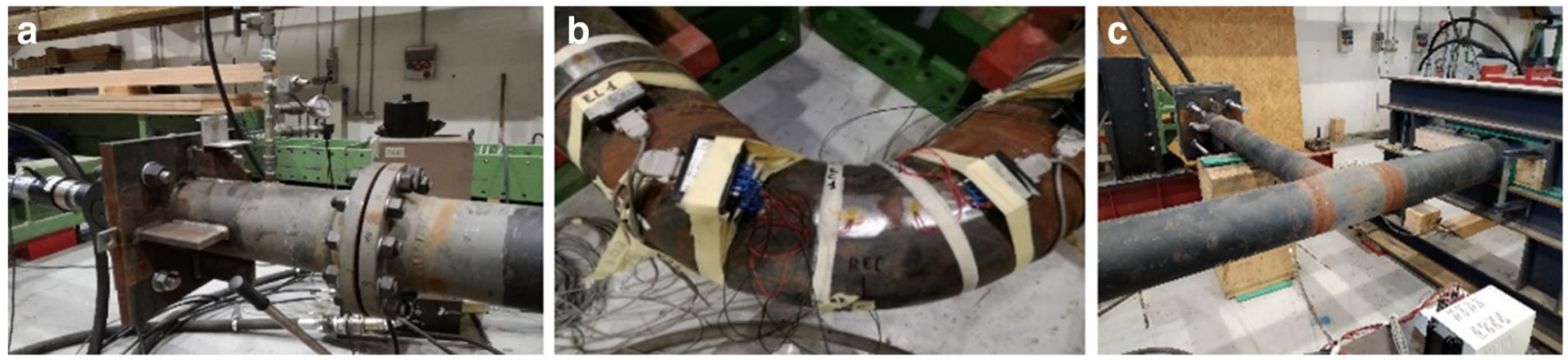

Fig. 11 Close up view of the experimental components. (a) bolted flange joint, (b) piping elbow and (c) Tee joint

Table 6 Simplified tank model parameters

\begin{tabular}{lll}
\hline Parameter & Value & Unit \\
\hline $\mathrm{E}$ & 210 & $\mathrm{GPa}$ \\
$\rho_{\text {fluid }}$ & 900 & $\mathrm{~kg} / \mathrm{m}^{3}$ \\
$\rho_{\text {tank }}$ & 7850 & $\mathrm{~kg} / \mathrm{m}^{3}$ \\
$c_{c}$ & 1690 & $\mathrm{Ns} / \mathrm{m}$ \\
$c_{i}$ & $1930 \times 10^{3}$ & $\mathrm{Ns} / \mathrm{m}$ \\
$\mathrm{H}$ & 14 & $\mathrm{~m}$ \\
$\mathrm{R}$ & 4 & $\mathrm{~m}$ \\
$m_{t}-$ steel tank mass & $1.65 \times 10^{4}$ & $\mathrm{~kg}$ \\
$m_{l}-$ liquid mass & $6.33 \times 10^{5}$ & $\mathrm{~kg}$ \\
$m_{c}-$ convective mass & $7.98 \times 10^{4}$ & $\mathrm{~kg}$ \\
$m_{i}-$ impulsive mass & $5.47 \times 10^{5}$ & $\mathrm{~kg}$ \\
\hline
\end{tabular}

According to these modified distributions, a new set of $4 \mathrm{e} 4$ artificial accelerograms is therefore generated combining $2 \mathrm{e} 2$ parameter realizations with $2 \mathrm{e} 2$ different baseline noises. Thus, from this set of artificial accelerograms, seven signals are selected to be tested with hybrid simulation. Among them, 4 are chosen to keep the system in the linear regime, equivalent to service limit state (SLS), and 3 to go slightly in non- linear regime to investigate ultimate limit state (ULS). This categorization is made upon $u_{\max }$, by setting $u_{\max }<0.04 \mathrm{~m}$ for SLS signals and $u_{\max }>0.06 m$ for ULS ones. The relevant spectral accelerations of these 7 accelerograms are depicted in Fig. 7 with SLS signals in blue and ULS in red.

More precisely, we selected an SLS signal, depicted in Fig. 8, with a PGA of $3.14 \mathrm{~m} / \mathrm{s}^{2}$ to be tested with hybrid simulation. We decided to adopt a low intensity signal in order to not induce any yielding into our system. As a matter of fact, we relied on the monotonic test to study the plastic behavior of the PS.

\section{Experimental Setup and Hybrid Simulations}

The experimental approach relies on the hybrid simulation technique [10]. More precisely, the unanchored tank is simulated via a numerical substructure (NS). Thus, the transfer system, i.e. a $250 \mathrm{kN}$ MTS actuator, enforces the compatibility between the NS and the physical substructure (PS) represented by the piping system. The PS is shown in Figs. 9, 10, 11.

Furthermore, the NS model is built with a simplified approach based on [16]. Along this line, the simplified
Fig. 12 Simplified tank model after [16]
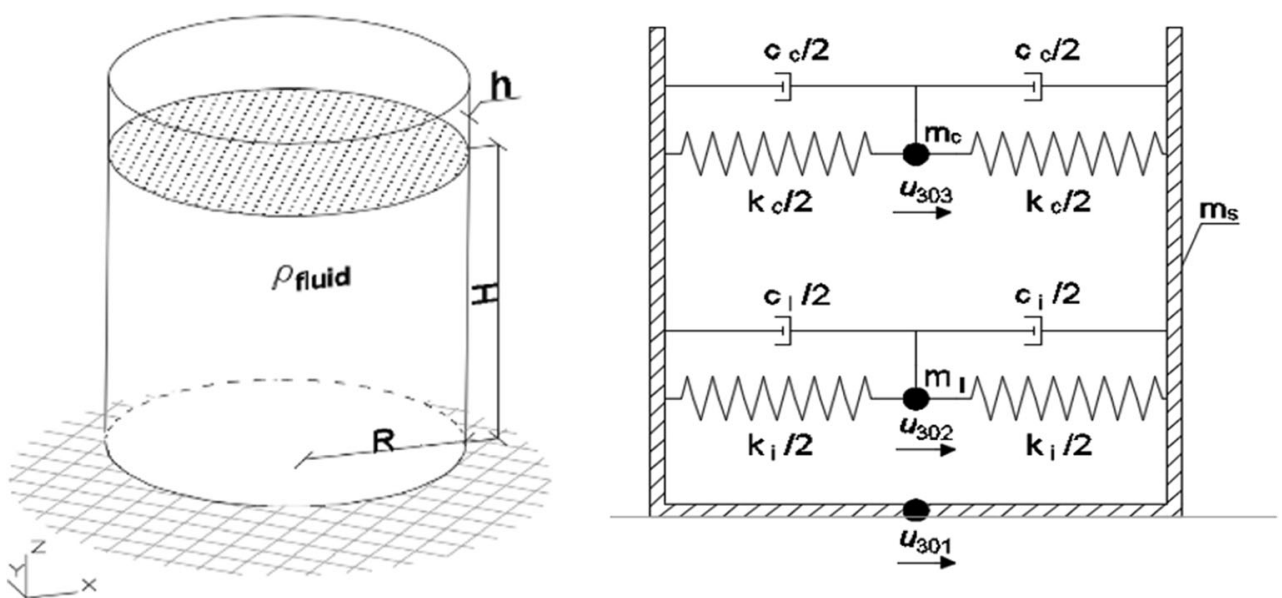
Fig. 13 Scheme of the hybrid simulation

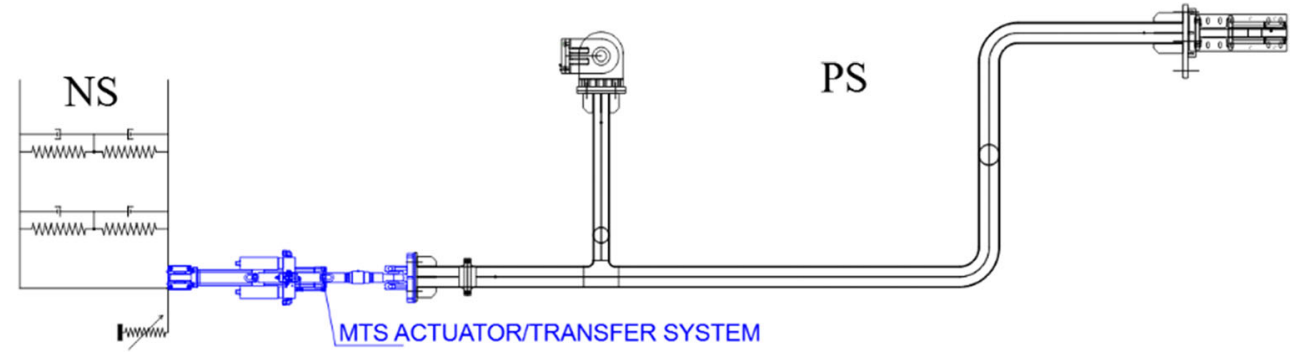

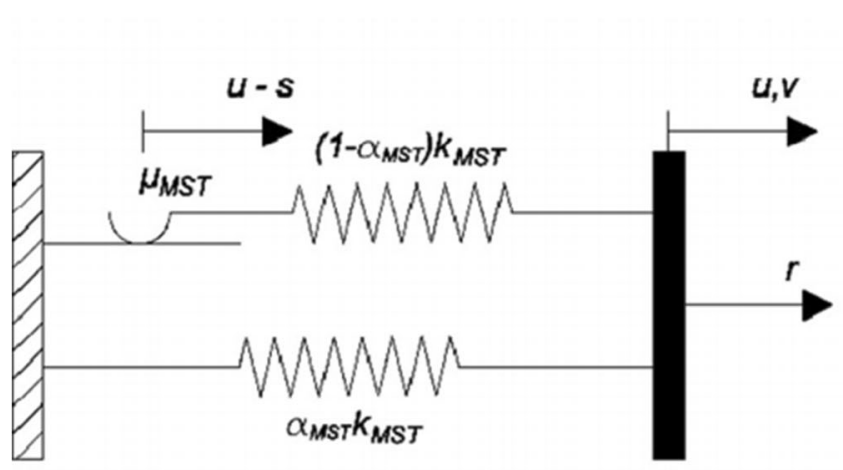

(a)

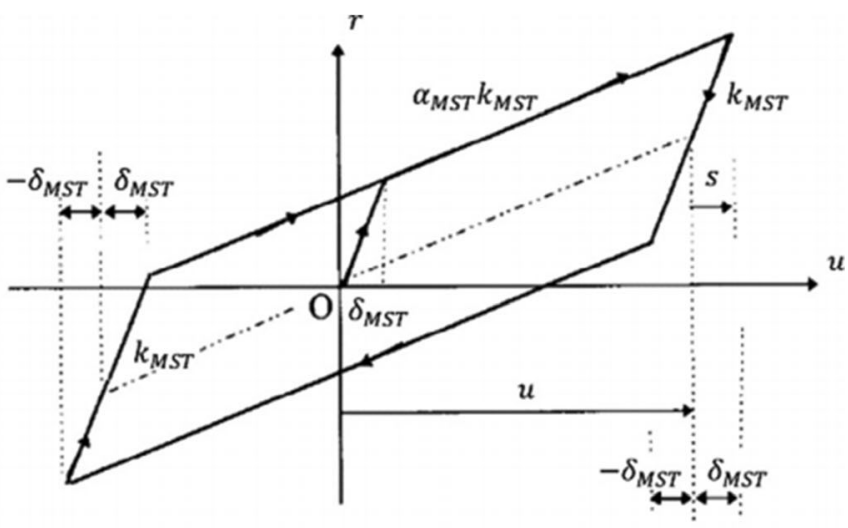

(b)

Fig. 14 Bilinear Mostaghel's model [17]: (a) SDoF idealization; (b) Hysteretic loop

tank model is given in Fig. 12 and the relevant parameters are reported in Table 6.

For clarity, the main scheme of hybrid simulation is shown in Fig. 13.

The sliding effect at the base of the tank is modelled by a friction contact model between the tank bottom and the concrete foundation. More precisely, the friction effect is implemented into the NS through the bilinear Mostaghel model [17].
In this respect, the main equations of the Mostaghel's model read,

$\left\{\dot{r},=,\left(\alpha_{M S T} k_{M S T}+\left(1-\alpha_{M S T}\right) k_{M S T}\left(\bar{N}(v) \bar{M}\left(s-\delta_{M S T}\right)+M(v) N\left(s+\delta_{M S T}\right)\right)\right), v,, \dot{u},=, v\right.$

where the parameter $s$ and the remaining functions $N, M, \bar{N}$
Fig. 15 Transfer system and signals in the hybrid simulation

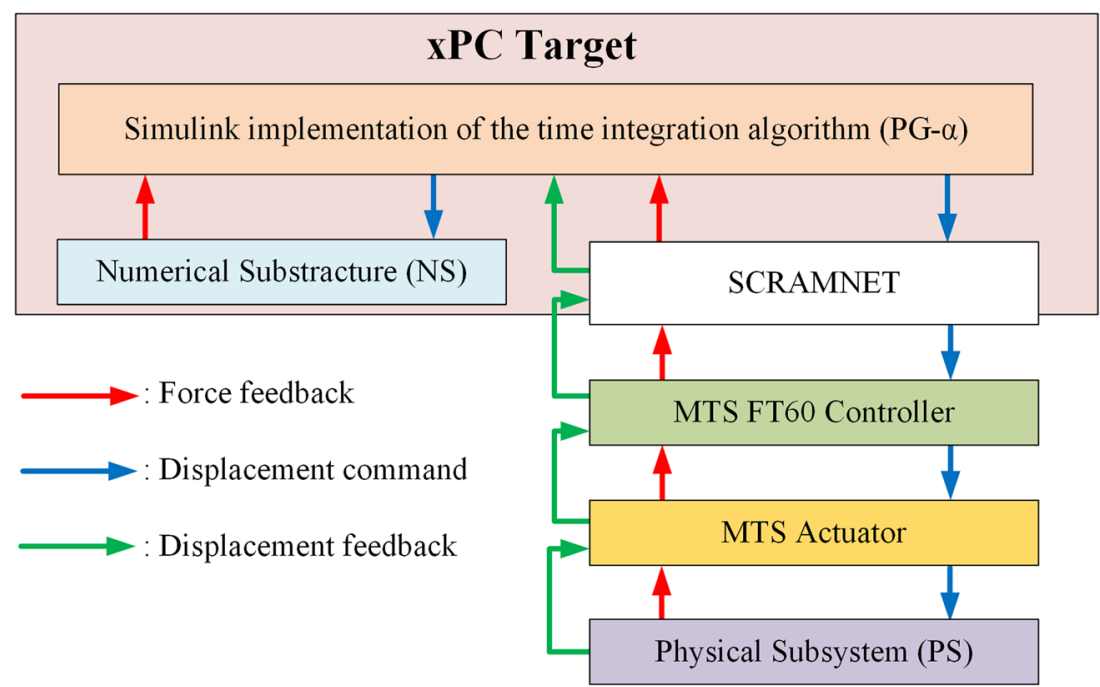




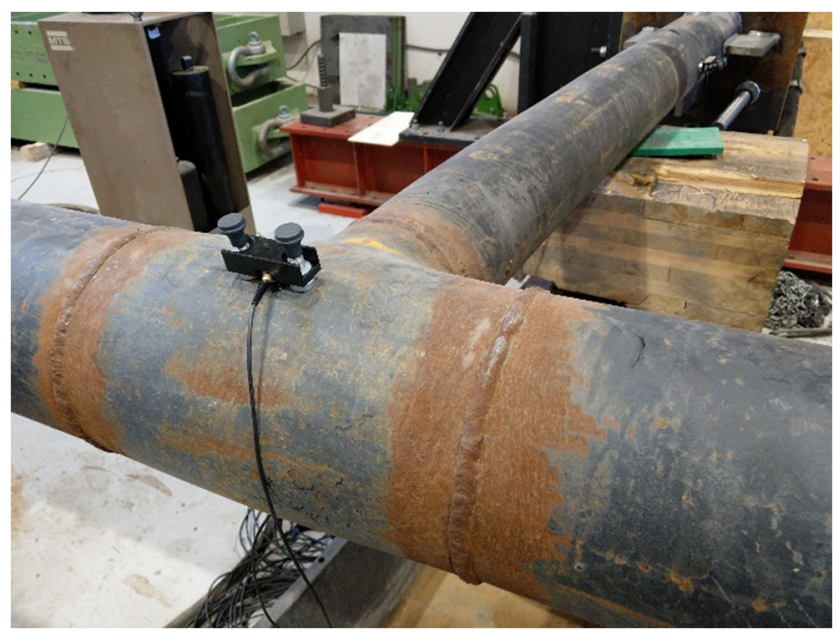

Fig. 16 Acoustic sensor installation on the Tee joint. Typical MAG4M

and $\bar{M}$ are defined as follows:

$$
\begin{gathered}
s=\frac{r-\alpha_{M S T} k_{M S T} u}{\left(1-\alpha_{M S T}\right) k_{M S T}} \\
N(v)=0.5(1+\operatorname{sgn}(v))(1+(1-\operatorname{sgn}(v))) \\
M(v)=1-N(v) \\
\bar{N}(v)=M(-v) \\
\bar{M}(v)+N(-v)
\end{gathered}
$$

Furthermore, parameters $k_{M S T}, \alpha_{M S T}$ and $\delta_{M S T}$ represent initial stiffness, post-yielding stiffness reduction factor, and yielding displacement of the idealized mechanical model, respectively. In order to replicate the friction phenomenon, these parameters are set as,

$$
\begin{gathered}
\delta_{M S T}=\Delta=1 e^{-3 m} \\
\alpha_{M S T}=1 e^{-3} \\
k_{M S T}=\frac{\mu\left(m_{l}+m_{t}\right) g}{\Delta}=2.18 e+8 \frac{N}{m}
\end{gathered}
$$
magnetic spring clips used to attach the VS150 sensor on the pipeline

For the sake of clarity, both a mechanical model and the entailing hysteretic behavior of the degrading system formalized by [17], is shown in the following figure (Fig 14).

More specifically, we assumed a friction coefficient for the interaction between steel and concrete equal to $\mu=0.1$, according to [18].

With regard to time integration adopted in HS, we relied on the Partitioned Generalized (PG- $\alpha$ ) algorithm [11]. It allows to decouple the computation time between NS and PS and assures the compatibility of velocities between the two domains by means of Localized Lagrange Multipliers. Moreover, the solution of the NS is evaluated through a linearly implicit predictor-corrector approach based on the trapezoidal rule with $\gamma=0.5, \beta=0.25$ and $\alpha=0$.

In order to carry out HSs, both mass and stiffness matrices were used to model the NS by means of the MATLAB/ Simulink code in the Host PC. The Host PC compiles the system of equations discretized in time by the Partitioned PG- $\alpha$ algorithm [11] which are then sent to an XPC target -a real time operating system installed in a target PC- via a LAN connection. During HS, the integration algorithm solves the equations of motion in the XPC target and estimates a displacement command for the PS. It is written in the XPC target, and this signal is instantaneously copied in the MTS controller through SCRAMNET -a reflective memory between the Host PC and the MTS controller-. The controller then commands the actuator to move the coupling DoF to the desired position. Again, the SCRAMNET memory instantaneously supplies the corresponding restoring force measured by a load cell to the xPC target, as depicted in Fig. 15.

A comparison between the target displacement computed and the measured one is used to assess the performance of the HS. In particular, the absolute ratio between the residual measured distance to the target displacement and the starting displacement position is calculated at each step. Thus, in order to guarantee an accurate solution within the actuator electronics limitations, a maximum value of 10-4 is imposed for this

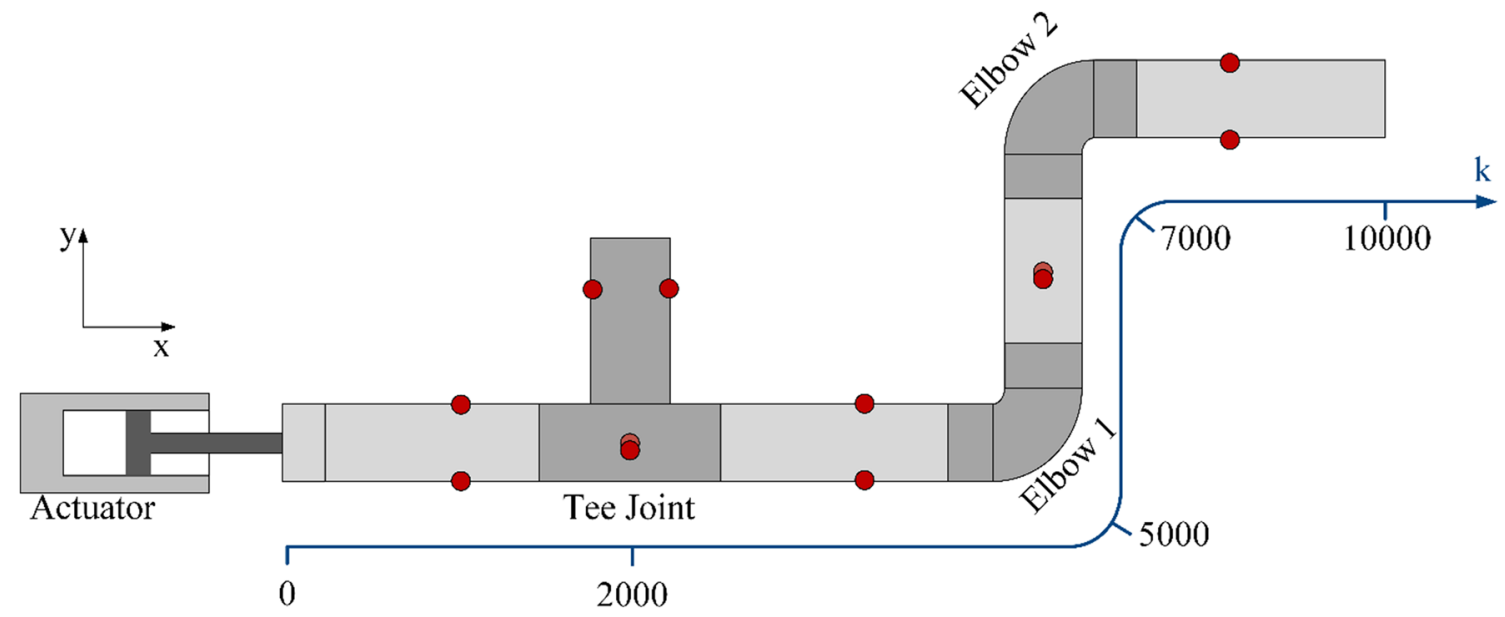

Fig. 17 Top view illustration of the pipeline. Red points correspond to the acoustic emission sensors. Dimensions in mm 


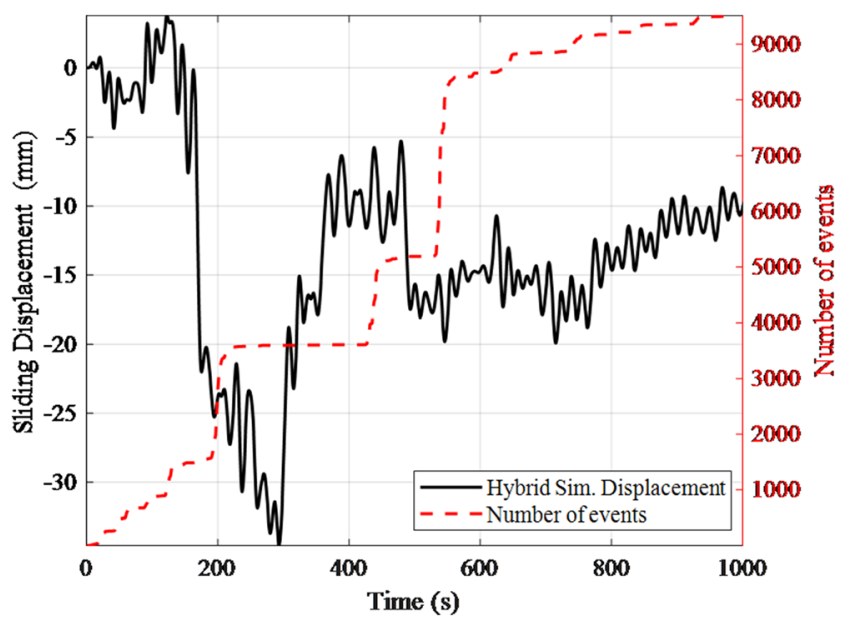

Fig. 18 Trends of displacements provided by hybrid simulation and acoustic emission events

ratio. Finally, a partitioned integration based on Localized Lagrange Multipliers (LLM) is used to enforce kinematic compatibility between velocities, at the interface between PS and NS [11].

\section{Acoustic Sensor Installation}

The piping system consists of three main critical components: i) a Tee joint; ii) Elbow \#1; iii) Elbow \#2. These components can experience stress concentrations during earthquake events due to both their geometry and their welding connections to the main pipeline. As a matter of fact, this study focuses on low-cycle fatigue of Tee joints and piping elbows while other components, like bolted flange joints, are found to be less vulnerable to this limit state [2]. Clearly, the LoC limit state is very important for a piping performance, but it is out of the scope of this paper.

Acoustic emission tests are carried out using an AMSY6 acoustic emission system, including 12 VS150 sensors with $150 \mathrm{kHz}$ resonant frequency, provided from Vallen Systeme

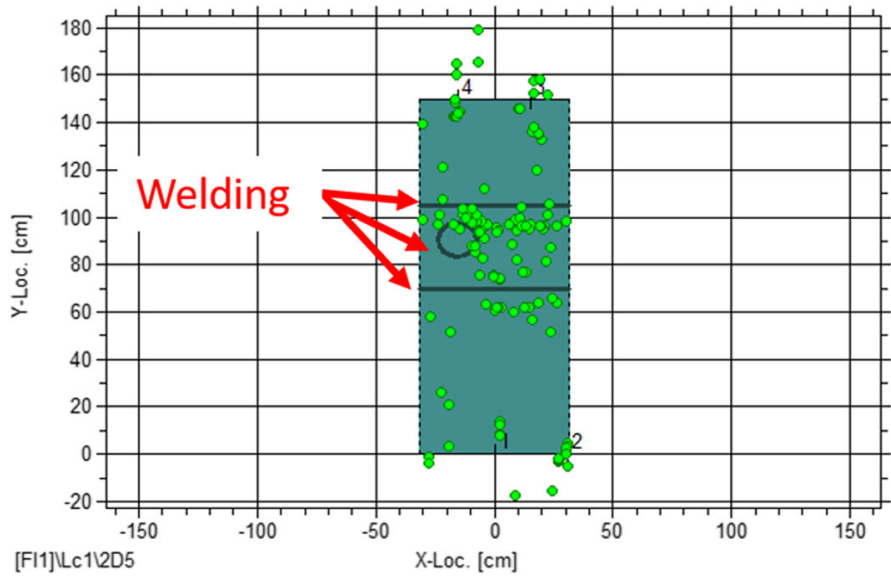

$\mathrm{GmbH}$. The sensors are attached to the pipeline components using a couplant liquid alongside with magnetic spring clips or adhesive tape as indicated in Fig. 16.

The exact placement of the sensors is illustrated in Fig. 17. Moreover, the acoustic emission events are measured and recorded in real time, including emission signals (hits), normalized energy, time of the event, rise time, and other relevant measures.

\section{Acoustic Emission Results}

The Tee joint, Elbow \#1, and Elbow \#2 components are linked to the main pipeline by means of welded connections. Naturally, weldments involve high residual stresses and more defects with respect to a monolithic component [19]. Hence, welded connections subjected to cyclic or dynamic loading can exhibit fatigue sensitive characteristics while flaws can trigger crack growth [20, 21]. Moreover, crack formation and its relevant growth mechanism can be detected and evaluated with a proper analysis of acoustic emission signals [22]. More precisely, in this study we measured acoustic emissions of the tank-piping system both during a seismic event and a monotonic loading. As a result, the evaluation of acoustic emission signals provided information about the health status of critical component connections as well as dislocation and deformation mechanisms of the pipe.

\section{Hybrid Simulation}

The response of the piping system is firstly examined by means of hybrid simulation using a synthetic ground motion record, i.e. the one depicted in Fig. 8. Moreover, the total duration of HS took sixteen minutes during which acoustic emissions signals were collected. The relationship between the acoustic emission events and displacements entailed by seismic input is illustrated in Fig. 18.

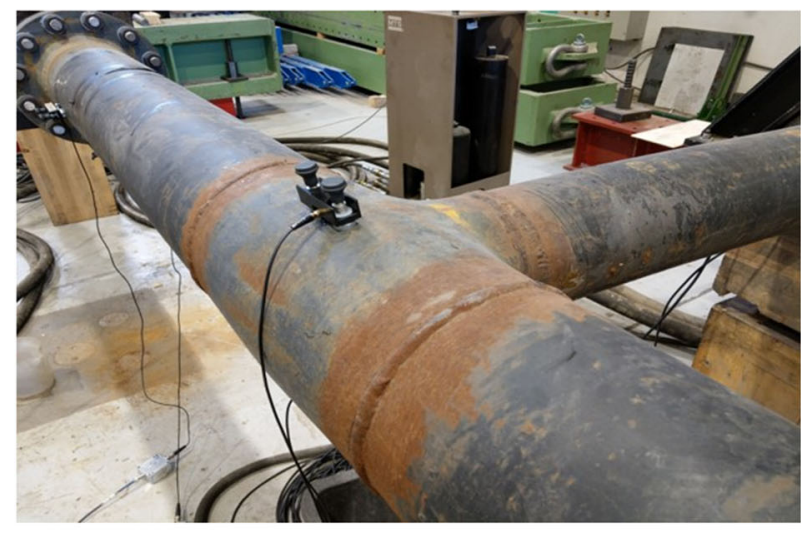

Fig. 19 Green points show acoustic emission signals detected on the Tee joint during the HS tests (left). Tee joint component (right) 

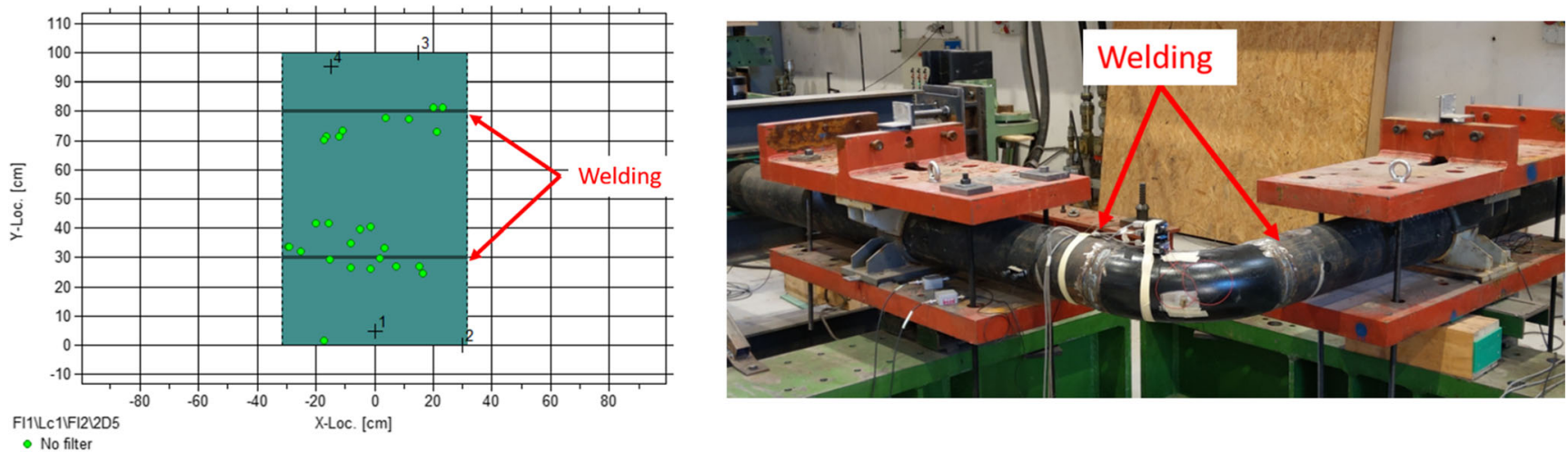

Fig. 20 Acoustic emission signals detected on Elbow \#1 (left). Elbow \#1 component (right)

One can notice from Fig. 18 that the number of acoustic emission signals proportionally increases with the longitudinal displacement of the pipeline system; this is a clear indication that the pipeline displacement triggers the deformation mechanisms through the pipeline material. Thus, in order to better understand the damage status of critical components, a volumetric monitoring approach is adopted with reference to Tee joint and Elbow \#1 depicted in Fig. 17. This approach is aimed at detecting and localizing cracks with an increased accuracy. As a matter of fact, test results show that most of the acoustic emissions are concentrated in welding connections of the examined components. More precisely, the collected acoustic emission signals and their locations for Tee joint and Elbow \#1, are presented in Figs. 19 and 20, respectively. Hence, relying on the emission signals data, the Tee joint is found to experience a higher level of deformation compared to Elbow \#1.

In order to reach a deeper understanding of the performance of both Tee joint and Elbow \#1 time-dependent emission signals are represented the frequency domain using the

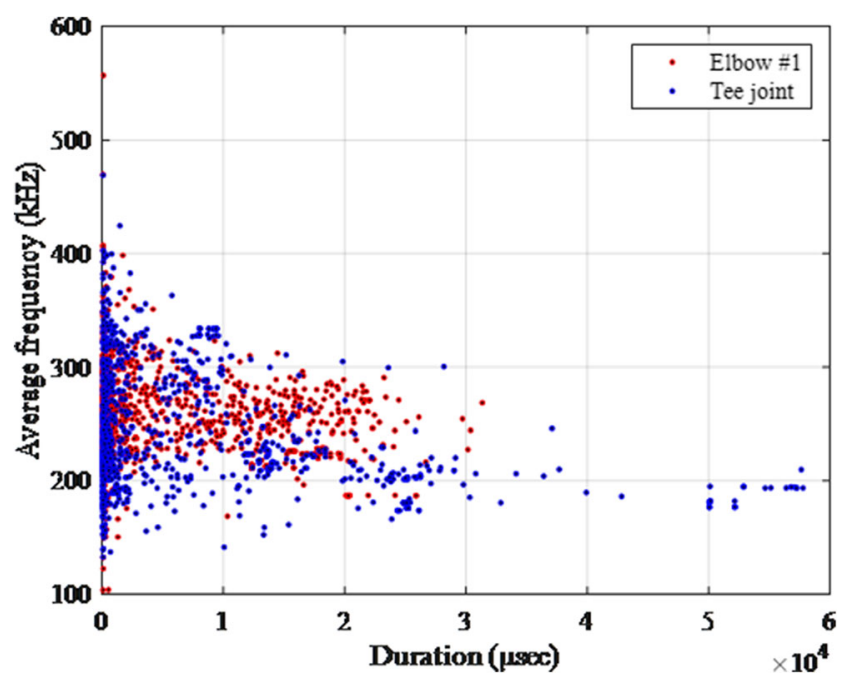

Fig. 21 Comparison of the events mean frequencies and durations of Tee joint and Elbow \#1
Fast Fourier Transform. The entailing mean frequency versus the total duration of each signal is reported in Fig. 21 too.

A careful reader can notice that both Tee joint and Elbow \#1 generate signals with a wide range of frequency values and different duration times. As a matter of fact, experimental data underline longer event durations for the Tee joint given to a large amount of welded connections subjected to damage.

\section{Monotonic Test}

In order to reach the collapse limit state, the piping system was subjected to a monotonic test. More precisely, the system was loaded by means of the transfer system up to $190 \mathrm{kN}$, corresponding to a maximum total displacement of $470 \mathrm{~mm}$. The relevant loading-displacement relationship including the cumulative number of relevant acoustic events is depicted in Fig. 22. A good correlation between the two set of data exist especially when the piping components enter in the plastic regime.

Furthermore, in order to understand the level of critical components damage occurred during the monotonic test, the location of acoustic emission events was

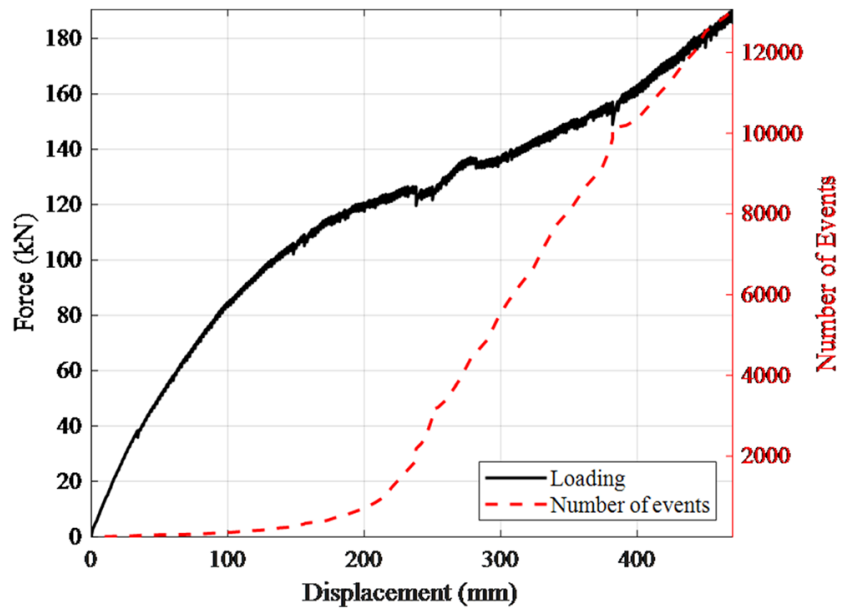

Fig. 22 Loading-displacement relationship of the piping system including the cumulative number of relevant acoustic events 


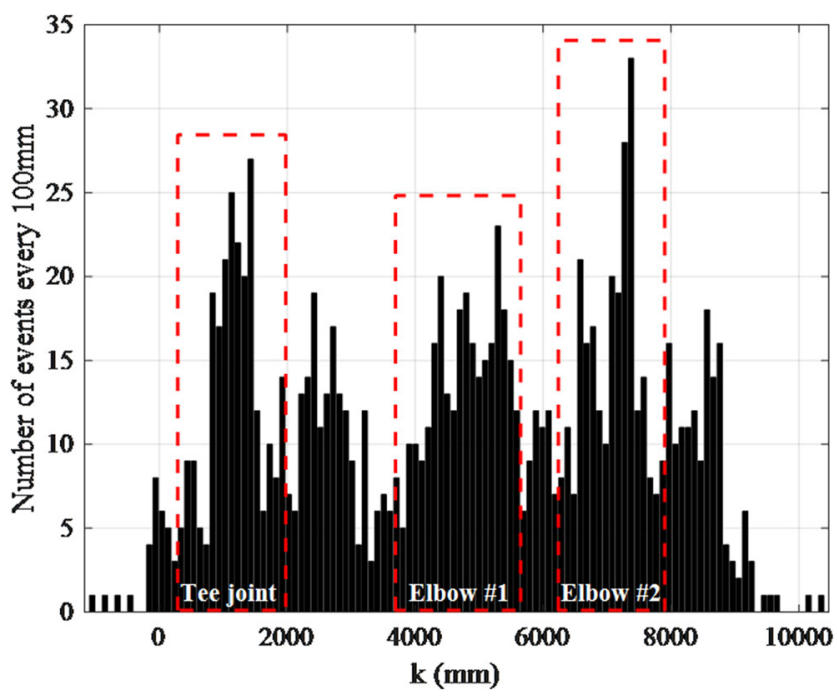

Fig. 23 Location-dependent number of events

investigated. Along this line, we divided the pipeline in $100 \mathrm{~mm}$ segments along the k-direction as shown in Fig. 17. Thus, for each segment, the total number of acoustic emission signals is evaluated and relevant event densities are depicted in Fig. 23. Both the Tee joint and Elbow \#2 result to be the most damaged components.

Moreover following [23], we analyzed in depth plasticity mechanisms in the pipeline. Therefore, the relationship between events amplitude and the total number of crack events, depicted in Fig. 24, was used to define both elastic and plastic regions all the way through. As a result, one can observe the first motion of dislocations, called Plasticity \#1, that exhibit low amplitude emissions of about $78 \mathrm{~dB}$. The following events, grouped as Plasticity \#2, were observed after $600 \mathrm{~s}$ with a maximum peak amplitude of about $100 \mathrm{~dB}$. Differently from the Plasticity \#1 phase, dislocation mechanisms of the material lose their importance in the Plasticity \#2 phase. Thus, liberation of dislocations, trigger permanent

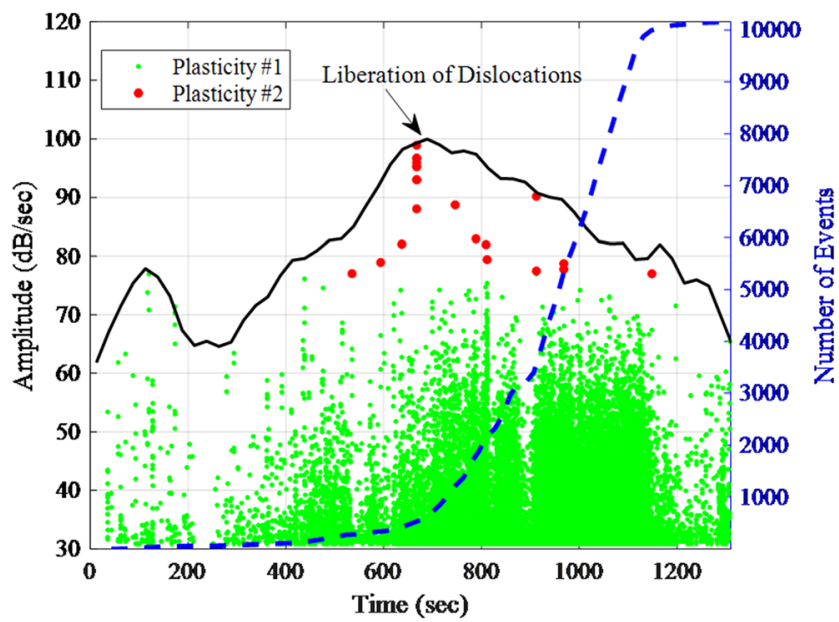

Fig. 24 Plasticity evaluation of the piping system subjected to monotonic loading deformations through the piping system and significant deformations start. Furthermore, after the beginning of the Plasticity \#2 region, the number of event activities exhibit a rapid increment. This trend can be correlated to the overall pipeline stiffness decrease with respect to the initial stiffness shown in Fig. 22.

\section{Conclusions}

In this article, we presented a methodology capable of assessing the vulnerability characteristics of a realistic tank-piping system based on hybrid simulation, synthetic ground motions and acoustic emission analysis. In particular, we focused on the performance of vulnerable components of the piping network. As a first step, we considered a seismic scenario that is associated with a geographical site using a probabilistic seismic hazard analysis. On this basis, we identified a seismic input by means of a stochastic ground motion model. In addition, in order to reach the collapse limit state of the piping system, a monotonic loading case was also considered. During both loading cases, the acoustic emission detection and localization was carried out during the experiments. Based on the performance evaluation of critical components based on acoustic emission events, the Tee joint resulted to be the most damaged component for the hybrid simulation case whilst Elbow \#2 was the most damaged component for the monotonic case. Thus, the acoustic emission technique let us to gather more in-depth information about damage level of critical components as well as the plasticity level of the piping system. This opens the way to collect a library of acoustic emission events for the classification of vulnerable component and to refine our finite elements models for future studies.

Acknowledgements This project has received funding from the Italian Ministry of Education, University and Research (MIUR) in the frame of the "Departments of Excellence" (Grant No. 232/2016); and the Italian National Institute for Insurance against Accidents at Work (Grant N. BRIC ID 16/2016).

Funding Information Open access funding provided by Università degli Studi di Trento within the CRUI-CARE Agreement.

Open Access This article is licensed under a Creative Commons Attribution 4.0 International License, which permits use, sharing, adaptation, distribution and reproduction in any medium or format, as long as you give appropriate credit to the original author(s) and the source, provide a link to the Creative Commons licence, and indicate if changes were made. The images or other third party material in this article are included in the article's Creative Commons licence, unless indicated otherwise in a credit line to the material. If material is not included in the article's Creative Commons licence and your intended use is not permitted by statutory regulation or exceeds the permitted use, you will need to obtain permission directly from the copyright holder. To view a copy of this licence, visit http://creativecommons.org/licenses/by/4.0/. 


\section{References}

1. Cruz AM, Steinberg LJ, Vetere-Arellano AL (2006) Emerging issues for natech disaster risk management in Europe. J Risk Res 9: 483-501. https://doi.org/10.1080/13669870600717657

2. Bursi OS, di Filippo R, La Salandra V, Pedot M, Reza MS (2018) Probabilistic seismic analysis of an LNG subplant. J Loss Prev Process Ind 53:45-60. https://doi.org/10.1016/j.jlp.2017.10.009

3. Caputo AC, Paolacci F, Bursi OS, Giannini R (2019) Problems and perspectives in seismic quantitative risk analysis of chemical process plants. J Press Vessel Technol 141

4. Cornell CA, Krawinkler H (2000) Progress and challenges in seismic performance assessment. PEER Center News 3:1-3

5. Der Kiureghian A (2005) Non-ergodicity and PEER's framework formula. Earthq Eng Struct Dyn 34:1643-1652. https://doi.org/10. 1002/eqe.504

6. Bommer JJ, A.B.A. (2004) The use of real earthquake Accelerograms as input to dynamic analysis. J Earthq Eng Imp Coll Press 8:43-91. https://doi.org/10.1080/13632460409350521

7. Baker JW (2008) An introduction to probabilistic seismic hazard analysis (PSHA). White paper, version, 1:72

8. Sanaz Rezaeian ADK (2010) Simulation of synthetic ground motions for specified earthquake and site characteristics. Earthq Eng Struct Dyn 39:1155-1180. https://doi.org/10.1002/eqe

9. La Salandra V, Di Filippo R, Bursi OS, Fabrizio SAP (2016) Cyclic response of enhanced bolted flange joints for piping systems. In: ASME 2016 Pressure Vessels \& Piping Conference

10. Abbiati G, La Salandra V, Bursi OS, Caracoglia L (2018) A composite experimental dynamic substructuring method based on partitioned algorithms and localized Lagrange multipliers. Mech Syst Signal Process 100:85-112. https://doi.org/10.1016/j.ymssp. 2017.07.020

11. Abbiati G, Lanese I, Cazzador E, Bursi OS, Pavese A (2019) A computational framework for fast-time hybrid simulation based on partitioned time integration and state-space modeling. Struct Control Heal Monit 26:e2419

12. Brownjohn JMW (2007) Structural health monitoring of civil infrastructure. Philos Trans R Soc A Math Phys Eng Sci 365:589-622. https://doi.org/10.1098/rsta.2006.1925

13. Di Filippo R, Abbiati G, Sayginer O, Covi P, Bursi OS, Paolacci F (2019) Numerical surrogate model of a coupled tank-piping system for seismic fragility analysis with synthetic ground motions. In: American Society of Mechanical Engineers, Pressure Vessels and Piping Division (Publication) PVP. American Society of Mechanical Engineers (ASME)

14. Sobol' IM (1993) Sensitivity estimates for nonlinear mathematical models. Math Modeling Comput Exp 1:407-414

15. Stefano Marelli BS (1996) a Framework for Uncertainty Quantification in MATLAB. Vulnerability, Uncertainty, Risk CASCE 2014, pp 2554-2563

16. Malhotra PK, Wenk T, Wieland M., (2000) Simple procedure for seismic analysis of liquid-storage tanks. Structural Engineering International, 3/2000, pp 197-201

17. Mostaghel N (1999) Analytical description of pinching, degrading hysteretic systems. J Eng Mech 125:216-224

18. Gorst NJSJ, Williamson S, Pallett PF, Clark LA (2003) friction in temporary works. Research report. Shool of engineering, the University of Birmingham, Health and Safety Executive, publication no. 071, Birmingham

19. Yu J, Ziehl P, Matta F, Pollock A (2013) Acoustic emission detection of fatigue damage in cruciform welded joints. J Constr Steel Res 86:85-91. https://doi.org/10.1016/j.jcsr.2013.03.017

20. Fisher JW (1984) Fatigue and fracture in steel bridges. Case studies. New York: Wiley

21. Fisher JW (1972) Fatigue strength of welded steel beam details and design considerations, Summary, January 1972 (72-5).Fritz Laboratory Reports.Paper 413. https://preserve.lehigh.edu/engrcivil-environmental-fritz-lab-reports/413

22. Yu J, Ziehl P, Zrate B, Caicedo J (2011) Prediction of fatigue crack growth in steel bridge components using acoustic emission. J Constr Steel Res 67:1254-1260. https://doi.org/10.1016/j.jcsr. 2011.03.005

23. Ennaceur C, Laksimi A, Hervé C, Cherfaoui M (2006) Monitoring crack growth in pressure vessel steels by the acoustic emission technique and the method of potential difference. Int J Press Vessel Pip 83:197-204. https://doi.org/10.1016/j.ijpvp.2005.12. 004

Publisher's Note Springer Nature remains neutral with regard to jurisdictional claims in published maps and institutional affiliations. 